\title{
APROXIMACIÓN A LA ENSEÑANZA DE LA RELIGIÓN EN EL SISTEMA JURÍDICO COSTARRICENSE
}

\author{
ENRIQUE HERRERA CEBALLOS*
}

\begin{abstract}
Resumen:
La realidad jurídica costarricense constituye una isla en el mar laico latinoamericano al ser el único país confesionalmente católico. Aun así y, más allá de mero positivismo jurídico, la jurisprudencia constitucional ha superado la idea de Estado confesional en favor del amplio reconocimiento del derecho de libertad religiosa. La coexistencia de estos principios trasciende el modelo de Estado y se proyecta en otros ámbitos como el educativo en el que el derecho a la libertad educativa ligado a la libertad religiosa, configuran un sistema peculiar que trataremos de exponer a continuación. Palabras clave: Estado confesional; libertad religiosa; educación religiosa.
\end{abstract}

\begin{abstract}
:
Nowadays, all Latin American countries are secular States. However, there is an exception: Costa Rica. It is the only Catholic confessional State from its beginning until today. However, although the Constitution proclaims the principle of denominational State, this idea was overcome by the constitutional jurisprudence in order to protect the right of religious freedom recognized in a few international agreements signed by the State as for example the American Convention of Human Rights. With this idea, the denominational State and the right of religious freedom must coexist and its consequences are transferred to all areas of law, as for example education. This is the area of our study and we will try to explain its legal system and the articulation between those two principles that seem contradictory.
\end{abstract}

Key words: Denominational State; religious freedom; religious education.

\section{CONFESIONALIDAD, TOLERANCIA Y LIBERTAD RELIGIOSA}

A pesar de algunos intentos de reforma constitucional en contra, en la actualidad el Estado costarricense es el único Estado iberoamericano de carácter confesional, tal como lo proclama su Constitución Política (en adelante CP). La invocación a Dios - al Dios cristiano, católico - del constituyente en el escueto Preámbulo ${ }^{1}$ y en el juramento requerido a los funcionarios públicos (art. $194 \mathrm{CP}^{2}$ ) resulta premonitoria de la consagración del principio de confesionalidad católica plasmado expresamente en el artículo 75 cuando se afirma que "La Religión Católica, Apostólica, Romana, es la del Estado, el cual contribuye

\footnotetext{
* Profesor Ayudante Doctor. Universidad de Cantabria (España).

1 “Nosotros, los Representantes del pueblo de Costa Rica, libremente elegidos Diputados a la Asamblea Nacional Constituyente, invocando el nombre de Dios y reiterando nuestra fe en la Democracia, decretamos y sancionamos la siguiente: CONSTITUCIÓN POLÍTICA DE LA REPÚBLICA DE COSTA RICA".

2 El texto reza ¿Juráis a Dios y prometéis a la patria, observar y defender la Constitución y las leyes de la República y cumplir fielmente los deberes de vuestro destino? -Sí juro-Si así lo hiciereis Dios os ayude si no, Él y la patria os lo demande.
} 
Enrique Herrera Ceballos: Aproximación a la Enseñanza de la Religión en el Sistema Jurídico Costarricense

a su mantenimiento, sin impedir el libre ejercicio en la República de otros cultos que no se opongan a la moral universal ni a las buenas costumbres".

Con independencia de que la Asamblea constituyente de 1949 discutiese o no sobre el carácter confesional del Estado ${ }^{3}$, parece que el texto actual del artículo 75 es casi un calco de los artículos 66 y 8 de las Constituciones de 1871 y $1917^{4}$ en los que se proclamaba que "La Religión Católica, Apostólica y Romana es la del Estado, el cual contribuye a su mantenimiento, sin impedir el libre ejercicio [en la República ${ }^{5}$ ], de ningún otro culto que no se oponga a la moral universal ni a las buenas costumbres".

Al Estado no le resulta indiferente el hecho religioso, hasta tal punto que se identifica con él y se compromete a sustentarlo económicamente en una de sus múltiples manifestaciones como es el catolicismo. Hecho que, por otro lado, no resulta extraño a la luz de la historia, teniendo en cuenta el papel decisivo de la Iglesia católica tanto en el proceso de colonización (1519-15236) como en el de configuración de la independencia ya en el siglo XIX, forjando alianzas con los representantes de la Nación emergente y, en contrapartida, imponiendo una determinada moral con substrato religioso ${ }^{7}$.

La Constitución no consagra pues la libertad religiosa - en sentido estricto- ni como derecho subjetivo ni como principio institucional; todo lo más alcanza al derecho de libertad de expresión, conciencia y opinión reconocidos subsiguientemente en los artículos 28 y 29 cuando dicen "Nadie puede ser inquietado ni perseguido por la manifestación de sus opiniones...» y «Todos pueden comunicar sus pensamientos de palabra o por escrito y publicarlos sin previa censura...". Puede hablarse por tanto de un discurso de mera tolerancia religiosa porque el Estado valora, en cierto modo, de forma negativa aquellas religiones que no sean la suya admitiendo, quizá como mal menor, otras manifestaciones cultuales distintas en el marco de la moral universal y las buenas costumbres con el objetivo de mantener la paz social.

\footnotetext{
${ }^{3}$ Las opiniones no son unánimes. A modo de ejemplo cfr. MAROTO VARGAS, A. La confesionalidad del Estado costarricense: un proceso en constante renovación, Revista Reflexiones, 92-2 (2013), p. 195; artículo en el que cita en este punto a CAMPOS, D. Relaciones Iglesia-Estado e Costa Rica: un estudio histórico-jurídico, Editorial Guayacán, San José, 2000 y, en contra OROZCO SOLANO, V. en La configuración de la libertad religiosa en el ordenamiento jurídico costarricense y la confesionalidad del Estado: un propuesta de reforma, Derecho y Religión, vol. X (2015), p. 107.

${ }^{4}$ Vigente únicamente dos años. Fue la de 1871 la que sirvió de base para la redacción de la actual. Cfr. ARCE GÓMEZ, C. (ed.) Constitución Política de la República de Costa Rica, Editorial Universidad Estatal a Distancia (EUNED), San José, 2004, p. VII.

${ }^{5}$ La referencia expresa a la República fue omitida en el artículo 8 de la Constitución de 1917.

${ }^{6}$ Cristóbal Colón fondeó en Puerto Limón en 1502 pero la conquista del istmo fue un proceso convergente que partió de México y Panamá entre 1519 y 1523, estabilizándose la organización política del territorio a partir de 1540. Cfr. al respecto MOLINA, I. Y PALMER, S. Historia de Costa Rica. Breve, actualizada y con ilustraciones, 1a edición, 4ạ reimpresión, Editorial de la Universidad de Costa Rica, San José, 2004, pp. 19-20.

${ }^{7}$ Cfr. OROZCO SOLANO, V. op. cit., p. 192.
} 
ISSN 0719-7160

La Carta Magna se queda en el estado previo a la libertad: la tolerancia ${ }^{8}$. Una visión anclada en tiempos pretéritos que implica privilegiar un culto frente a los demás al suponer que existe una clara superioridad teológica de un credo en particular sobre los otros. Visión ésta que oscurece la posibilidad del pleno ejercicio de la libertad de creencias porque en la opción va implícita una cierta prevención para con los acatólicos que puede llevar a obstaculizar alguna de las múltiples manifestaciones que la religión lleva aparejada.

Dicho esto, es de justicia poner de manifiesto que, a día de hoy, existen voces que se alzan en contra de la confesionalidad estatal ${ }^{9}$ reclamando la apertura hacia la laicidad, al entender que es el sistema que mejor garantiza la máxima amplitud en el reconocimiento del derecho fundamental de libertad religiosa.

Aunque indubitadamente el Estado reviste carácter confesional y, en consecuencia, no se puede predicar la existencia de un derecho que imponga la neutralidad religiosa con carácter genera ${ }^{10}$, la cláusula de tolerancia contenida en el artículo 75 CP ha permitido a la Sala Constitucional de la Corte Suprema de Justicia conciliar, en cierto modo, aquel principio con el de libertad religiosa ${ }^{11}$, defendiendo una interpretación y aplicación restrictiva del confesionalismo al considerar que éste se agota en tener a la religión católica como oficial y contribuir a sus sustento en la medida en que este modelo de Estado colisiona con el derecho de libertad religiosa, reconocido por otra parte, en los Tratados In-

\footnotetext{
8 "Donde hay derechos fundamentales y se tiene la posibilidad real de exigirlos y hacerlos cumplir, la tolerancia resulta insuficiente, queda empequeñecida y para seguir siendo tiene que ser otra cosa de lo que durante siglos ha sido o se ha pretendido que fuera" Cfr. TOMÁS Y VALIENTE, F. A orillas del Estado, Taurus, Madrid, 1996, p. 227, recogido en el Prólogo a la obra de SOLAR CAYÓN, J. I. La teoría de la tolerancia en John Locke, Dykinson, Madrid, 1996, p. 16.

${ }^{9}$ El Dr. Víctor Orozco sostiene que “... lo ideal es que tanto la religión estatal como las no oficiales se movilicen, o realicen sus actividades en un plano de igualdad, a partir de un marco de laicidad en el cual el Estado mantiene un comportamiento neutro o indiferente sobre cualquier agrupación religiosa...", ídem. p. 108. Vid. también el proyecto de Ley de reforma de los artículos 75 y 194 CP (Expediente no 18496) presentado a la Asamblea Legislativa con fecha de 27 de junio de 2012. Asamblea Legislativa, de la República de Costa Rica, Centro de Información [consulta 11.03.2016]. Disponible en: http://www.asamblea.go.cr/Diputadas Diputados/dipda_carmen_mu\%C3\%B1oz/proyectos munoz/Proponente\%20de\%20Proyectos\%20de\%20Ley/Proyecto-18496.pdf

${ }^{10}$ Sentencia no. 1732-2014 de la Sala Constitucional de la Corte Suprema de Justicia (en adelante SCCSJ). Sala Constitucional de la Corte Suprema de Justicia, Jurisprudencia, Fallos Relevantes (2015) [consulta 17.03.2016]. Disponible en: http://sitios.poder-judicial.go.cr/salaconstitucional/Centro\%20de\%20Jurisprudencia/Sentencias\%20relevantes/ACCIONES\%20Y\%20CONSULTAS\%20RELEVANTES\%202015.pdf

${ }^{11}$ Cuyo contenido ha sido fijado por la jurisprudencia constitucional en la Sentencia SC-CSJ no. 9768, de 13 de junio de 2008. En ella se dice expresamente que el artículo 75 CP "garantiza la libertad religiosa y de culto de los individuos y las comunidades...". Cfr. Ministerio de Educación, Dirección de Asuntos Jurídicos [consulta 17.03.2016]. Disponible en: http://mep.go.cr/sites/default/files/criterios_y pronunciamientos/Libertad\%20de\%20culto,\%20asistencia\%20a\%20lecciones.pdf
} 
Enrique Herrera Ceballos: Aproximación a la Enseñanza de la Religión en el Sistema Jurídico Costarricense

ternacionales suscritos por Costa Rica como la Declaración Universal de Derechos Humanos (art. 18), el Pacto Internacional de Derechos Civiles y Políticos (art. 18) o la Convención Americana de Derechos Humanos (art. 12).

La jurisprudencia defiende, en consecuencia, que el carácter confesional "debe interpretarse no como un indicador de parcialidad de la Constitución en beneficio de una confesión religiosa determinada, sino como un indicador de una realidad sociológica, cual es la mención expresa a la confesión indiscutiblemente más arraigada y extendida en nuestro país, lo que en ningún momento implica una discriminación por parte de los poderes públicos para las demás confesiones o para los ciudadanos confesionales"12.

De la cláusula de tolerancia la Sala extrae además dos presupuestos tendentes al reconocimiento de la libertad religiosa en el país como son: a) la obligación que pesa sobre el Estado de no impedir el libre ejercicio de otros cultos - distintos del católico- que no sean contrarios a la moral universal y a las buenas costumbres y, b) la operatividad del principio de cooperación con las confesiones religiosas acatólicas que, de acuerdo con la legislación vigente, merezcan reconocimiento.

A fortiori, el Tribunal deduce la necesidad de conciliación de los principios antedichos, no sólo de la prohibición de las limitaciones arbitrarias a la libertad religiosa contenida expresamente en el artículo 75 sino acudiendo a la interpretación sistemático-constitucional; "a los principios que definen el andamiaje democrático-institucional del pais"13, de forma que el artículo 75 debe entenderse a la luz de otros valores constitucionales como el reconocimiento de lo espiritual como informador del resto del principios configuradores del Estado - principio democrático, principio representativo, institucionalidad democrática y libre sistema electoral - , el derecho a la igualdad de trato ante la Ley y no discriminación consagrado en el artículo $33^{14}$ y el derecho de libertad de conciencia, pensamiento y opinión reconocido — según la Sala - en el artículo $28.1^{15} \mathrm{CP}$.

En suma, la jurisprudencia consciente de que la confesionalidad resulta un tanto contraria a las más modernas tendencias del derecho constitucional comparado ha aprehendido la libertad religiosa como un principio informador más del Estado social y democrático de Derecho perfectamente articulable con la existencia de una religión de Estado de forma

\footnotetext{
12 Resolución SC-CSJ no. 2010014175, de 25 de agosto de 2010. Cfr. Poder Judicial de la República de Costa Rica, Sala Constitucional, Constitución Política y Principios Anotados con Jurisprudencia [consulta 17.03.2016]. Disponible en: http://sitios.poder-judicial.go.cr/salaconstitucional/Constitucion\%20Politica/Sentencias/2010/10-014175.html

${ }^{13}$ Textualmente en la sentencia no. 4575-2104 SC-CSJ.

14 “Todo hombre es igual ante la ley y no podrá hacerse discriminación alguna contraria a la dignidad humana".

15 “Nadie puede ser inquietado ni perseguido por la manifestación de sus opiniones ni por acto alguno que no infrinja la ley".
} 
ISSN 0719-7160

que "Ia Constitución de 1949 armoniza el Estado confesional con la libertad religiosa, entendida como un valor constitucional preciado y de primer orden"16 que obliga a respetar el pluralismo religioso y que, a la sazón, resulta uno de los pocos lugares en el mundo "donde se equilibra el Estado confesional con el respeto a la libertad religiosa"17.

\section{EL PRINCIPIO DE SEPARACIÓN ENTRE RELIGIÓN Y EDUCACIÓN}

El título VI de la CP costarricense se dedica íntegramente a la "Religión". Sin embargo el articulado del mismo resulta exiguo pues se reduce a un solo precepto, el antes referido, artículo 75. No existen más referencias de carácter religioso en la Carta Magna salvo las concernientes a los principios de confesionalidad y tolerancia religiosa.

Puesto que la afirmación precedente tiene carácter absoluto y no existen excepciones, se colige necesariamente que la Constitución no contempla la religión como materia obligatoria en la educación en sus diversos grados, tal y como atestigua el Título subsiguiente (VII), que regula "La Educación y la Cultura" (arts. 76-89). La educación religiosa no forma parte de la concepción del constituyente en la configuración básica de la educación ya fuere pública ya privada; ámbitos que, expresamente, se reconocen.

El hecho circunstancial referido ha llevado a la jurisprudencia a afirmar que existe un principio de separación entre la religión y la educación en la concepción constitucional originaria. La polaridad de esferas conlleva que al Estado, aun confesional, le está vedado imponer determinados contenidos religiosos en la educación pública o privada. Por el contrario "los poderes públicos deben procurar el pleno ejercicio y goce de la libertad y la tolerancia religiosa como valor constitucional fundamental que asegura una coexistencia pacífica y armónica del conglomerado social, más aún cuando la realidad muestra una gran diversidad y heterogeneidad religiosa que se ha ido incrementando desde la promulgación de la Constitución de 1949. En el terreno educativo, el Estado costarricense está llamado y obligado a respetar el principio de la neutralidad religiosa"18.

\footnotetext{
${ }^{16}$ Sentencia no. 2023-2010 SC-CSJ. Cfr. Poder Judicial de la República de Costa Rica, Sala Constitucional, Constitución Política y Principios Anotados con Jurisprudencia [consulta 17.03.2016]. Disponible en: http://sitios.poder-judicial.go.cr/salaconstitucional/Constitucion\%20Politica/Sentencias/2010/10$\underline{002023 . h t m l}$

${ }^{17}$ Sentencia no. 1732-2014 SC-CSJ. Cfr. también en CERVANTES, L. F. Los principios generales sobre la libertad religiosa en la jurisprudencia de los sistemas europeo, interamericano y costarricense de protección de los Derechos Humanos, publicado por la Corte Interamericana de Derechos Humanos en http://www.corteidh.or.cr/tablas/r26333.pdf, p. 132-134.
}

${ }^{18}$ Sentencias no 2023-2010 SC-CSJ, Considerando V y no. 4575-2014 SC-CSJ. 


\section{LA NEUTRALIDAD COMO EXIGENCIA DEL DERECHO INTERNACIONAL}

De acuerdo con la jurisprudencia al Estado no sólo le está vetado incluir unos contenidos curriculares religiosos en el sistema educativo público y privado por mor del mandato constitucional sino que los Instrumentos Internacionales en materia de Derechos Humanos suscritos por Costa Rica inciden positivamente en esta obligación de interdicción puesto que constituyen parámetros de constitucionalidad tal y como obliga el artículo 48 $\mathrm{CP} 19$.

Según la Sala, el principio de aconfesionalidad en la educación vendría amparado conforme al Derecho Internacional Público por la Declaración Universal de Derechos Humanos (art. 26.2), la Convención relativa a la lucha contra las discriminaciones en la esfera de la enseñanza (art. 5.1.a)) y el Pacto Internacional de los Derechos Económicos, Sociales y Culturales (art. 13.1) en los que se consigna que una de las finalidades de la educación es «la comprensión, la tolerancia y la amistad entre todas las naciones y todos los grupos étnicos o religiosos» o la Declaración Americana de Derechos y Deberes del Hombre de 5 de mayo de 1948, (art. 12.1), en donde se dice que "Toda persona tiene derecho a la educación, la que debe estar inspirada en los principios de libertad, moralidad y solidaridad humanas".

De acuerdo con estos presupuestos normativos, el Estado costarricense estaría obligado a observar la laicidad en la ordenación de la educación pública a fin de asegurar la consecución de los valores de tolerancia, comprensión y entendimiento entre las diferentes opciones religiosas posibles con el fin último de garantizar la paz social. De este modo la actuación del Estado en este ámbito - la educación pública- debe caracterizarse por la abstención de cualquier tentación de imponer determinados contenidos curriculares religiosos, aun cuando el Estado es formalmente confesional, con el objetivo de que sea una educación libre y pluralista ${ }^{20}$.

Por otro lado, el derecho de los padres a que sus hijos reciban la educación moral y religiosa que esté de acuerdo con sus convicciones (arts. 18.4, del Pacto Internacional de Derechos Civiles y Políticos y 12.4 de la Convención Americana sobre Derechos Humanos) queda garantizado por dos vías. La primera sería la configuración constitucional de la educación privada que, en Costa Rica, no sólo es una opción más sino que queda sometida al amparo estatal en la medida en que los Poderes Públicos resultan garantes de su

\footnotetext{
19 "Toda persona tiene derecho al recurso de habeas corpus para garantizar su libertad e integridad personales, y al recurso de amparo para mantener o restablecer el goce de los otros derechos consagrados en esta Constitución, así como de los otros derechos consagrados en esta Constitución así como de los de carácter fundamental establecidos en los instrumentos internacionales sobre derechos humanos, aplicables en la República".

${ }^{20}$ Sentencia no. 2023-2010, Considerando VII.
} 
ISSN 0719-7160

impulso y fomento y, la segunda, por medio de la introducción de "un contenido ecuménico o bien más elástico u optativo de la materia de religión en la educación pública", en consonancia con lo dispuesto por el artículo 5.1‥b) de la Ley Número 3170 de 12 de agosto de 1963 por la que el Estado se adhirió a la Convención relativa a la Lucha contra las Discriminaciones en la Esfera de la Enseñanza (14.12.1960) que impide compeler a cualquier individuo o colectividad a recibir instrucción religiosa incompatible con sus convicciones ${ }^{21}$.

Sobre este aspecto abunda y concluye la Sala que el hecho de no obligar a recibir una concreta educación religiosa no es garantía suficiente en la protección de los valores constitucionales (igualdad, dignidad humana, libre desarrollo de la personalidad, tolerancia, libertad religiosa [sic], etc.) sino que la acción del Estado debe encaminarse bien a garantizar - suponemos que en la educación pública - una instrucción religiosa de carácter ecuménico o bien conforme al credo religioso específico que se profese ${ }^{22}$.

\section{LA NEUTRALIDAD RELIGIOSA EN EL ÁMBITO EDUCATIVO}

La aplicación del principio de neutralidad religiosa en la educación obligaría a los poderes públicos a adoptar una posición aconfesional para — según la Sala - "promover y fomentar la diversidad y libertad religiosa"23; afirmación ésta que aunque en un contexto distinto pudiere resultar un tanto extraña, se adecua a la realidad jurídica del país en cuanto la CP prevé que sea el Estado quien, de alguna forma, promueva o fomente la diversidad religiosa a través del estímulo a la educación privada ${ }^{24}$.

A renglón seguido y dándose un salto lógico en la argumentación jurídica, la Sala Constitucional extrapola el - presunto- principio de aconfesionalidad que rige en el ámbito educativo a la totalidad del texto constitucional, afirmando que "conforme al principio de la neutralidad religiosa, los poderes del Estado deben interpretar los conceptos constitucionales con fundamento en criterios de aplicación neutrales y que resulten válidos para todos, esto es, de manera no confesional o vinculada a una creencia religiosa en particular"25.

\footnotetext{
21 Ibíd.

22 Ibíd. in fine.

${ }^{23}$ Sentencia no. 2023-2010, Considerando VI.

${ }^{24}$ Artículo 80. La iniciativa privada en materia educacional merecerá estimulo del Estado, en forma que indique la ley (La cursiva es nuestra).

${ }^{25}$ Sentencia no. 2023-2010, Considerando VI.
} 
Enrique Herrera Ceballos: Aproximación a la Enseñanza de la Religión en el Sistema Jurídico Costarricense

Según su criterio la actuación neutral del Estado en la adopción de la totalidad de las políticas públicas deriva de una serie de valores y principios constitucionales que, a continuación se desgranan: 1‥ La consagración del principio republicano, al que es consustancial - dice el Tribunal - la secularización de la esfera pública y, por consiguiente, el respeto de la libertad religiosa y de la neutralidad confesional del Estado en materia educativa; 2 . El respeto a la dignidad humana de la que dimana el principio de igualdad (art. $33 \mathrm{CP}$ ) de toda persona con independencia de cuáles sean sus convicciones, creencias o concepciones religiosas; 3‥ La configuración de la sociedad democrática [sic] (art. 1 CP) y, en consecuencia, "pluralista en lo ideológico y confesional y tolerante, siendo que los poderes del Estado tienen la interdicción de promover, en el campo educativo, un solo credo religioso". Del mismo modo - sigue razonando el Tribunal- existen otros valores constitucionales de los que se infiere "una clara tendencia laica [sic]... y a consagrar el principio de la separación - por lo menos imperfecta- entre la esfera religiosa y el ámbito político, administrativo, judicial y electoral", como por ejemplo el veto a los clérigos para acceder a determinados cargos políticos o la prohibición de hacer propaganda política invocando la religión como arma de convicción; restricciones éstas que "dejan patente la intención del constituyente originario de separar la esfera política y administrativa de la órbita religiosa, evitando intersecciones inconvenientes que puedan frustrar el goce y ejercicio de ciertos derechos fundamentales y humanos de carácter básico" 26.

\section{LA ORDENACIÓN LEGAL DE LA EDUCACIÓN RELIGIOSA}

A diferencia de otros países como Colombia o Perú en los que existe una Ley de Libertad Religiosa ${ }^{27}$ que de una forma expresa se refiere al derecho a recibir e impartir educación religiosa en el ámbito escolar ${ }^{28}$, en Costa Rica aun a pesar de su peculiaridad, el desarrollo normativo del fenómeno religioso ha sido más bien escaso y, a día de hoy, no existe una norma similar en su ordenamiento jurídico.

Tal y como ha quedado patente ha sido la jurisprudencia constitucional la que ha desarrollado la extensión y alcance de la confesionalidad estatal intentando deducir principios y valores que la hagan compatible con la libertad religiosa, partiendo no obstante, de la cláusula de tolerancia que, ab initio, la acompaña según dispuso la Asamblea Constituyente de 1949.

\footnotetext{
${ }^{26}$ Ibíd. in fine.

${ }^{27}$ Ley no. 29635, de Libertad Religiosa peruana y Ley no. 133, de 23 de mayo de 1994 de Libertad religiosa y de cultos de Colombia.

${ }^{28} \mathrm{El}$ artículo 3.d) de la Ley peruana reconoce, como manifestación individual de la libertad religiosa "Elegir para sí o para los menores o los incapaces sujetos a su patria potestad, dentro y fuera del ámbito escolar, la educación religiosa y moral que esté de acuerdo con sus propias convicciones". Por su parte el artículo 6.h) de la Ley colombiana reza «Elegir para sí y los padres para los menores o los incapaces bajo su dependencia, dentro y fuera del ámbito escolar, la educación religiosa y moral según sus propias convicciones. El tenor literal de los preceptos es casi idéntico al artículo 2.c) de la Ley orgánica 7/1980 de Libertad Religiosa de España; ley que se tuvo en cuenta para la redacción de las dos precedentes.
} 
ISSN 0719-7160

Esta reflexión puede trasladarse a la regulación del alcance del hecho religioso en la educación, de forma que en la actualidad, son dos normas las que concitan el grueso de la ordenación legal: el Código de Educación ${ }^{29}$ y la Ley Fundamental de Educación ${ }^{30}$.

El artículo $210^{31}$ del Código establece tres premisas para con la religión en las escuelas de primera enseñanza (educación primaria):

1‥ Que la religión católica resulta una materia de obligada oferta.

2‥ Que han de dedicarse dos horas semanales a su impartición.

3․ Que la asistencia del alumnado resulta obligatoria.

4‥ Que existe una excepción a la regla anterior siempre que los padres de los educandos lo soliciten por escrito ante el Director del centro educativo.

5‥ Que se contemplan profesores de religión como docentes específicos de la materia.

En cuanto al alcance en los diferentes niveles educativos, aunque el artículo referido circunscribe la enseñanza religiosa únicamente a las "escuelas de primera enseñanza", en la práctica se extiende a la enseñanza secundaria de acuerdo con el criterio manifestado por el Departamento de Educación Religiosa del Ministerio de Educación Pública en el Oficio no. 50-2004 de 13 de febrero. Resulta curiosa la conclusión a la que llega la Administración porque extiende el efecto de la norma "por no existir norma expresa"32; circunstancia que no deja de sorprender por su escaso rigor jurídico.

Por su parte la Ley Fundamental de Educación, aunque no hace referencia explícita a la introducción de la religión como materia específica en los currícula escolares sí que configura el hecho religioso como elemento de cierta importancia en los fines que ha de perseguir la instrucción de niños y jóvenes.

Por un lado y, a nuestro juicio de una forma implícita pero necesariamente deducible del texto, el artículo 2으. al mencionar los fines que debe cumplir la educación, en su apartado b) cita la contribución al desenvolvimiento pleno de la personalidad humana; hecho éste que conecta necesariamente al individuo con "lo religioso" porque la religión constituye uno de los aspectos inherentes al ser humano que, como tal, ha de contribuir a su pleno

\footnotetext{
${ }^{29}$ Ley no. 181 que aprueba el Decreto no. 7, de 26 de febrero de 1944.

${ }^{30}$ Ley no. 2160, de 24 de septiembre de 1957.

${ }^{31}$ Así reformado por el artículo 1 de la Ley no. 48, de 15 de febrero de 1945.

32 Resolución SC-CSJ n‥ 2006-007247, Resultando 2ㅇ. Cfr. OROZCO SOLANO, V. El contenido esencial y los alcances de la libertad de religión. Especial referencia al ordenamiento jurídico alemán, español y costarricense, Revista Iberoamericana de Derecho Procesal Constitucional, 9 (2008), p. 215.
} 
Enrique Herrera Ceballos: Aproximación a la Enseñanza de la Religión en el Sistema Jurídico Costarricense

desarrollo personal. Por otro lado, los artículos 3, 13 y 14 del texto sí que contemplan la religión como un valor al que el sistema público de enseñanza debe tender a desarrollar.

En concreto, el primero de los preceptos establece que "Para el cumplimiento de los fines expresados [art. 2], la escuela costarricense procurará: b) El desarrollo intelectual del hombre y sus valores éticos, estéticos y religiosos. La afirmación de una vida familiar digna, según las tradiciones cristianas, y de los valores cívicos propios de una democracia"; el segundo de ellos reza "La educación primaria tiene por finalidades: h) Cultivar los sentimientos espirituales, morales y religiosos, y fomentar la práctica de las buenas costumbres según las tradiciones cristianas" y el tercero "La Enseñanza Media [...] tiene por finalidades: b) Afirmar una concepción del mundo y de la vida inspirada en los ideales de la cultura universal y en los principios cristianos".

Por otro lado queda patente la presencia de la religión en la educación a través de las competencias que se otorgan a la "Sección de Educación Religiosa" del Ministerio de Educación Pública entre las que se encuentran (art. $5^{33}$ ):

"1. Promover la enseñanza de los principios y valores cristianos, dentro del contexto de la cultura costarricense, de acuerdo con las características de los distintos grupos, comunidades locales y comunidades estudiantiles;

2. Anunciar y profundizar el mensaje cristiano en forma sistemática y progresiva para propiciar el diálogo entre fe y cultura;

3. Mejorar la calidad de la educación religiosa en la educación formal, así como en la no formal e informal".

\section{LA PERSPECTIVA ECUMÉNICA EN LA EDUCACIÓN RELIGIOSA}

Partiendo del principio de interpretación restrictiva de la cláusula de confesionalidad del Estado, en virtud del papel que juegan determinados principios y valores del derecho constitucional e internacional público que no pueden desconocerse, la jurisprudencia ha adoptado una visión particular de la misión que ha de jugar la enseñanza de la religión en la educación pública y, en consecuencia, de la propia naturaleza de la misma.

De acuerdo con los principios de libertad religiosa, separación y neutralidad del Estado en las esferas religiosa y educativa, la jurisprudencia ha entendido que no hay base jurídica para sostener que el Constituyente optara por reducir la educación religiosa a la católica, es más, declara expresamente esta premisa como abiertamente inconstitucional. En apoyo de este argumento aduce una interpretación - a nuestro juicio, y ya veremos

33 Decreto Ejecutivo 17051-MEP, de 20 de junio de 1986 por el que se establecen sus objetivos y funciones. Sistema costarricense de información jurídica (SCIJ) [consulta 15.03.2016]. Disponible en: http://www.pgrweb.go.cr/scij/Busqueda/Normativa/Normas/nrm texto completo.aspx?pa-

ram1=NRTC\&nValor1=1\&nValor2=9519\&nValor3=84058\&strTipM=TC\#ddown 
ISSN 0719-7160

por qué, un tanto sui generis - de la legislación ordinaria ${ }^{34}$ en cuya virtud las finalidades que persigue la educación religiosa - garantizar la dignidad humana, la tolerancia, la igualdad y los derechos humanos en general- imponen necesariamente -el adverbio es nuestro pero parece adecuado- una educación pluriconfesional ${ }^{35}$.

En el Estado costarricense parece que solo éste modelo garantizaría el respeto a los derechos humanos aludidos. Sensu contrario, luego imponiendo un modelo religioso concreto, se conculcarían estos derechos al excluir a los educandos que no lo profesen amén del derecho que les asiste a recibir la educación moral y religiosa que esté de acuerdo con sus propias convicciones según los Acuerdos Internacionales suscritos por el Estado costarricense. "El Estado no cumpliría adecuadamente sus obligaciones internacionales - aun cuando sí las impuestas por su Derecho interno ${ }^{36}$ - sólo dispensando a los alumnos no católicos de la clase de religión ${ }^{37}$ sino que su óptima satisfacción pasaría bien articulando la posibilidad de que aquellos reciban instrucción de la religión que profesen o, en su caso, adoptando una perspectiva religiosa ecuménica en la enseñanza religiosa"38.

La adopción de esta postura pluriconfesional ha conllevado la propuesta de un nuevo modelo educativo que, en lo religioso, se divide en dos fases. La primera, en la que se debe garantizar la formación religiosa consecuente con las creencias del educando que deberá ser impartida por personas idóneas al efecto y, la segunda - quizá en educación secundaria-, en la que el Estado adoptaría un enfoque ecuménico -ecléctico dice el Tribunal- que habría de fomentar los derechos humanos ${ }^{39}$ (libertad, dignidad, tolerancia, etc.).

Este modelo de educación religiosa mixta conlleva un sistema de selección del profesorado también mixto. Así la idoneidad de los profesores de "religión confesional" se valorará atendiendo a dos criterios: a) la idoneidad académica y, b) la autorización otorgada por la confesión religiosa correspondiente; criterio éste que según la Sala no resultará

\footnotetext{
${ }^{34}$ La Sala sólo se refiere al artículo 210 del Código de Educación y al artículo 2 de la Ley Fundamental de Educación.

${ }^{35}$ Sentencia no. 2023-2010, Considerando VIII.

${ }^{36}$ Cfr. artículo 210 del Código de Educación.

${ }^{37}$ Resolución SC-CSJ no. 2006-007247, de 23 de mayo. En el caso, aun cuando la autoridad educativa no tramitó la solicitud de dispensa de la clase de religión católica por advertirse un defecto formal - no estaba firmada por el responsable del menor-, de facto constaba que el centro docente respetó el derecho del estudiante de no recibir educación religiosa pues no se le examinó ni se tramitó ausencia alguna (Resultando no. 3, in fine).

${ }^{38}$ Sentencia no. 2023-2010, Considerando VIII.

39 Ibíd. Considerando IX.
} 
Enrique Herrera Ceballos: Aproximación a la Enseñanza de la Religión en el Sistema Jurídico Costarricense

absoluto ni determinante. Por otro lado, la idoneidad de los profesores de religión pluriconfesional ${ }^{40}$ o ecuménica vendrá avalada únicamente por su formación académica y, en su caso, por la superación de pruebas de acceso objetivas; en ningún caso se valorará a la hora de acceder a la docencia la habilitación confesional.

\section{EL DERECHO A SER DISPENSADO DE LA ENSEÑANZA RELIGIOSA}

El párrafo segundo del artículo 210 del Código de Educación contempla la excepción a la regla de obligatoriedad a la asistencia a la clase de religión católica.

Todos los educandos - y entendemos por tales a niños y jóvenes entre la educación primaria y la secundaria ${ }^{41}$ - quedan obligados a recibir educación católica salvo que sus padres soliciten la exención mediante escrito dirigido al director del centro educativo, el cual comunicará la lista de eximidos al inspector o visitador - del Ministerio de Educación- a efectos de su correspondiente archivo.

La Resolución 2006-007247 SC-CSJ que resolvió el recurso de amparo contra el director y el profesor de religión del Colegio redentorista San Alfonso de Alajuela de 3 de abril de 2006 declaró haber lugar al amparo del alumno por violentarse el derecho de petición reconocido expresamente en artículo 27 de la CP.

El 17 de marzo del mismo año el educando - un menor de edad-solicitó, mediante escrito firmado por él mismo, no participar en la educación religiosa por motivos de conciencia. Según consta en los hechos, el profesor devolvió la nota al alumno conminándole a que fuere firmada, además, por alguno de sus progenitores (Resultando no. 3). Consta igualmente que el centro, aun de facto y a pesar de que la solicitud se presentó tras un mes de iniciado el curso académico, respetó la decisión manifestada por el alumno no siendo evaluado de la materia ni tramitando ausencia alguna (Resultando no. 3 in fine).

Partiendo de estos presupuestos el Tribunal recuerda la normativa vigente sobre la exención de la obligatoriedad de asistir a clase de religión católica. Lo parco del artículo 210 del Código de Educación se ha visto complementado con el criterio aplicativo del Ministerio de Educación Pública, quien en una Circular de 5 de mayo de 1983 -declarada vi-

\footnotetext{
${ }^{40}$ Dicha se la expresión con todas las reservas por lo contradictorio de los términos que la conforman.

${ }^{41}$ La Dirección de Asuntos Jurídicos del Ministerio de Educación Pública en la Respuesta a solicitud sobre consulta de lecciones de educación religiosa en escuelas unidocentes (DAJ-109-C-2013, fechada el 18 de diciembre), punto no. 1 dice textualmente «La enseñanza de la educación religiosa tiene, en Costa Rica, carácter obligatorio en todos los centros educativos que imparten los niveles de primer y segundo ciclo de la Educación General Básica, según lo dispuso el legislador mediante el artículo 210 del Código de Educación...». Ministerio de Educación Pública, Dirección de Asuntos Jurídicos [consulta 18.03.2016]. Disponible en: http://mep.go.cr/sites/default/files/criterios_y_pronunciamientos/Lecciones\%20semanales\%20de\%20Educaci\%C3\%B3n\%20Religiosa.pdf
} 
ISSN 0719-7160

gente por Oficio no. DER-203 de 1 de agosto de 2000 - fijó el procedimiento administrativo a seguir al efecto. Dicho procedimiento exige la presentación de un escrito dirigido al director, que habrá de ser firmado por el padre o el encargado [sic] del alumno y que finalmente habrá de presentarse en el momento de formalizar la matrícula, esto es, al principio del curso académico ${ }^{42}$.

A pesar de que el centro educativo cumplió con la normativa procedimental, e incluso puede inferirse buena fe en su actuar al respetar la voluntad del alumno aun cuando no ajustada a Derecho, la Sala resolvió el asunto concediendo el amparo constitucional por considerar que el defecto de forma en la solicitud quedaba, de algún modo sanado por la aptitud para el ejercicio del derecho de petición; derecho que de acuerdo con el artículo 12 de la Convención sobre los Derechos del Niño y el artículo 5 del Código de la Niñez y la Adolescencia es directamente ejercitable por menores, aunque secundum quid, en la medida en que sus opiniones habrán de ser tenidas en cuenta por los Poderes Públicos en función de su grado de madurez. A tenor de este extremo, el Tribunal considera que resulta aplicable al caso porque el menor es un adolescente que cursa el último año de educación diversificada ${ }^{43}$. Está pues en condiciones - presumimos según el razonamiento de la Sala - que conformar autónomamente su conciencia en materia religiosa.

Nos llama la atención que la Sala conceda el amparo por violación del derecho de petición, sin - a nuestro juicio- sustanciarse lo esencial, esto es, el derecho de los padres a que sus hijos reciban la educación moral y religiosa que esté de acuerdo con sus propias convicciones.

De un modo un tanto anecdótico y sin pretensión de enmendar la plana a nadie, entendemos que en otros ordenamientos la solución jurídica no pasaría por atender al derecho de petición, toda vez que el mismo debe deslindarse del derecho de instancia cuando - éste - regula la iniciación de un procedimiento a instancia del interesado; procedimiento, siempre y en todo caso, reglado; no sometido a discrecionalidad administrativa. En este sentido, el ejercicio del derecho de petición stricto sensu se circunscribe a sugerencias, quejas, iniciativas, informaciones o súplicas en el ámbito -y esto es lo esencialen el ámbito de lo graciable y discrecional. Aplicando este criterio al caso, no estaríamos ante el ejercicio del derecho de petición sino ante el derecho de instancia por cuanto el ordenamiento contempla un procedimiento administrativo ${ }^{44}$. Cuestión distinta $-y$ he aquí el quid de la cuestión- es si debe atenderse la capacidad de discernimiento del

\footnotetext{
${ }^{42}$ Resolución SC-CSJ no. 2006-007247, Resultando 2o, apartado f.

${ }^{43}$ Ibíd. Considerando III; recogido por la doctrina en CERVANTES, L. F. op. cit., p. 135.

${ }^{44}$ Cfr. MARTín Rebollo, L. Leyes Administrativas, 15a ed. Thomson-Reuters, Navarra, 2009, comentario al artículo 29 de la Constitución española, p. 137.
} 
Enrique Herrera Ceballos: Aproximación a la Enseñanza de la Religión en el Sistema Jurídico Costarricense

alumno a tenor de su edad y madurez en presencia de una laguna jurídica, pues el Código de Educación sólo contempla a los padres como titulares del derecho a solicitar la exoneración; derecho que pasivamente recae sobre los educandos.

\section{LA LIBERTAD DE CULTO DE MINORÍAS RELIGIOSAS EN EL ÁMBITO EDU- CATIVO}

El descanso semanal no sólo es un derecho meramente secular sino que tiene su proyección religiosa específica y, en consecuencia, su problemática siempre y cuando choque con la tradición cultural y religiosa mayoritaria del territorio donde se pretenda ejercitar.

La pretensión de practicar el culto y descansar un día de la semana distinto del establecido oficialmente por la tradición y la norma del Estado lleva a conflictos en los que el derecho al trabajo, la libertad de empresa o el derecho a la educación pueden colisionar con el derecho de libertad religiosa. Este último caso de conflicto es el que nos atañe. ¿Cómo ha solventado la jurisprudencia costarricense la colisión de derechos?

Partiendo del reconocimiento de que la libertad religiosa conlleva, como manifestación ínsita, la práctica del culto, la Sala Constitucional ha venido reconociendo el derecho del alumnado - en sus diferentes etapas educativas - a ser eximido de clases y/o pruebas que se desarrollen en días en los que, de acuerdo con su religión, han de practicarse actos de culto. Eso sí, partiendo de que el derecho de libertad religiosa no es un derecho omnímodo, el reconocimiento efectivo de su ejercicio está sometido a ciertos condicionantes de tipo procedimental en aras a garantizar el adecuado desarrollo de las actividades educativas.

La jurisprudencia considera que la negativa a reprogramar exámenes o pruebas de evaluación ordinarias (estandarizadas) o extraordinarias - máxime éstas - resulta irrazonable, contraria al derecho de libertad religiosa y de culto y al derecho de cooperación y no injerencia de los poderes públicos en las creencias religiosas del alumnado.

El sistema educativo, en su labor de instrumento de progreso y promoción social debe garantizar el derecho de acceso a la educación sin más limitaciones que las derivadas de la capacidad intelectual y psíquica del educando. Por ello el ejercicio de la libertad de culto no debe ser impedimento de acceso a la educación; es más, el sistema educativo debe amparar la libertad religiosa tal y como afirma la Sala en la sentencia no. 11515-02, de 6 de diciembre de $2002^{45}$.

\footnotetext{
${ }^{45}$ Ministerio de Educación Pública, Dirección de Asuntos Jurídicos [consulta 17.03.2016] Disponible en: http://mep.go.cr/sites/default/files/criterios_y_pronunciamientos/Libertad\%20de\%20culto,\%20asistencia\%20a\%20lecciones.pdf
} 
ISSN 0719-7160

Favorecer el derecho de libertad religiosa en el ámbito educativo ha supuesto otorgar preferencia al ejercicio del derecho de libertad religiosa y de culto sobre obligaciones contractuales. De este modo se amparó el derecho de una trabajadora del sistema educativo superior (Universidad) que pertenecía a una congregación religiosa acatólica frente a las obligaciones derivadas del contrato y que imponían actividad académica en sábado; día que la actora debía dedicar a cumplir con sus obligaciones religiosas. Claramente se da preferencia al derecho fundamental frente a la obligación inter privatos y se conmina a la Universidad a autorizar a la trabajadora a programar sus exámenes en día distinto del sábado ${ }^{46}$.

La doctrina en este sentido está claramente consolidada ${ }^{47}$ en favor de la primacía de la libertad religiosa sobre las obligaciones académicas como demuestran las últimas sentencias de la Sala en las que se recuerda - casi mántricamente- que el "Tribunal ha reconocido el derecho de las personas estudiantes a que las autoridades educativas adopten medidas como la reprogramación de exámenes con el fin de conciliar su derecho a la educación con las prácticas de su credo religioso" 48.

Fijado el criterio general, sin embargo, el reconocimiento del derecho del alumno está sometido a una serie de criterios procedimentales ulteriores y, en su caso, a la existencia de condiciones materiales suficientes para su satisfacción efectiva pues en algunos casos se dispensa a los centros educativos de su obligación de modificar las fechas de docencia y/o exámenes cuando no existen posibilidades reales de realización sobre la máxima "nadie está obligado a lo imposible" [sic]. Dicho lo cual la correcta canalización del ejercicio de la libertad de culto exigen tres condiciones: a) prueba de pertenencia a una organización religiosa reconocida; b) conocimiento de la autoridad académica que se da a través de la correspondiente solicitud efectuada por escrito y, c) existencia de condiciones adecuadas para conciliar la actividad académica con las actividades cultuales ${ }^{49}$.

\section{OBSERVACIONES FINALES}

\footnotetext{
${ }^{46}$ Sentencia CS-CSJ no. 15326, de 10 de octubre de 2008.

${ }^{47}$ A modo de ejemplo sentencias SC-CSJ nos. 9768-08; 15326-08; 8791-09; 17309 o 2063-12, principalmente referidas a Iglesia Adventista del Séptimo Día. Vid. la totalidad de sentencias dictadas al respecto hasta 2012 en Poder Judicial de Costa Rica, Sala Constitucional, Jurisprudencia Constitucional (1989-2012) [consulta 02.05.2016] http://sitios.poder-judicial.go.cr/salaconstitucional/Centro\%20de\%20Jurisprudencia/Amparos\%20y\%20Habeas\%20Jurisprudencia\%20Constitucional/EDUCACl\%C3\%93N.pdf

${ }^{48}$ Sentencia CS-CSJ no. 2015-002776, no. 009414-15 y no. 017845-15.

${ }^{49}$ Sentencia CS-CSJ no. 15326, de 10 de octubre de 2008.
} 
Resulta evidente que el modelo de confesionalidad costarricense es más formal que material; es una confesionalidad atenuada por la pujanza del reconocimiento de la libertad religiosa sobre la mera tolerancia en virtud del peso que adquiere el Derecho internacional público que - según el art. 7 CP — forma parte del derecho interno del Estado.

La acción de la libertad religiosa en la concepción del hecho religioso ha llevado a la jurisprudencia constitucional a predicar el principio de neutralidad entre lo religioso y lo educativo y, con ello, a afirmar la vigencia de la aconfesionalidad en el sistema educativo del país.

Sin embargo hay algunos aspectos del razonamiento de la Sala Constitucional que no dejan de llamarnos la atención y que no podemos sustraernos a indicar:

1‥ El hecho de que en el Preámbulo constitucional se haga una invocación a Dios expresamente ha dado lugar a que se afirme que el resto de principios constitucionales - de índole estrictamente civil o secular - se hayan de interpretar en clave espiritual. Sin embargo no acabamos de entender la superposición de planos; religioso y secular salvo en su entendimiento neorregalista. ¿Cómo se interpreta el principio democrático o de representación institucional en clave religiosa o espiritual?

2‥ La jurisprudencia también ha afirmado que la interpretación restrictiva de la cláusula de confesionalidad se sustenta, entre otros principios y valores constitucionales, en el derecho de libertad de conciencia, pensamiento y opinión del artículo 28.1드. Esto nos plantea dos problemas: 1‥ Que del tenor literal del artículo sólo se infiere la libertad de expresión pues dice que "Nadie puede ser inquietado ni perseguido por la manifestación de sus opiniones...", de modo que harto complicado se hace advertir la libertad de conciencia y, 2o. Que el Tribunal no distingue entre libertad de conciencia y libertad religiosa cuando, in radice, son dos libertades distintas resultando círculos concéntricos en los que la libertad religiosa quedaría subsumida, por la más amplia, libertad de conciencia.

3‥ El hecho de que se sustente la aconfesionalidad del Estado en materia religiosa en el hecho de que la Constitución regule separadamente la religión del sistema educativo. En otras palabras, se sostiene que como la Carta Magna no indica que la religión sea materia obligatoria en la educación el Estado no está legitimado para imponerla.

Este razonamiento, a nuestro juicio, resulta inconsistente porque no atiende a la visión global del ordenamiento, en la medida en que el Código de Educación sí contempla la religión, y en concreto la católica, como materia obligatoria. Y es más, ha de ser la católica 
ISSN 0719-7160

la obligatoria porque los fines a los que tiende el sistema educativo según la ley Fundamental de Educación se centran, esencialmente, en la inculcación del cristianismo.

4ㅇ․ A nuestro juicio cuando el Tribunal extiende la separación religión-educación al resto del sistema jurídico realiza injustificadamente un salto lógico al desconocer la acción - aun cuando atenuada- del artículo 75 CP que, necesariamente, hace imbuir al Estado en un halo de religiosidad que libremente ha adoptado.

Por otro lado cuando se habla de que existen numerosos valores constitucionales que avalan predicar que el Estado tiende - jurídicamente- hacia la laicidad se hacen referencias un tanto insustanciales o, cuando menos, cuestionables como son:

a) La consideración de que al modelo político republicano le es consustancial la secularización. Esta idea es más que cuestionable en cuanto República y hecho religioso no son conceptos excluyentes porque existen Repúblicas de carácter confesional (v. gr. República Islámica de Irán o República Islámica de Mauritania).

b) El respeto a la dignidad humana derivada de la igualdad; hecho éste en el que no tiene por qué influir negativamente la confesionalidad del Estado en la medida en que el catolicismo no se contrapone ni a la igualdad ni a la dignidad humanas sino todo lo contrario, potencia su consecución.

c) La referencia a la construcción de una sociedad democrática, pluralista y tolerante; referencia ésta que no se contrapone con la confesionalidad del Estado porque el pluralismo - político, religioso, etc. - está ínsito en la sociedad con independencia del modelo estatal -otra cosa es que el Estado intente impedirlo- y el fomento de una sociedad tolerante - en lo religioso- queda garantizado por el propio artículo 75 CP.

5‥ El diseño de un modelo de educación religiosa mixta - confesional en una etapa y ecuménica en otra - resulta, a nuestro modo de ver, un tanto anómalo.

Se hace mucho hincapié, quizá por un cierto complejo de interferencia negativa del confesionalismo, en la neutralidad y de la tolerancia como instrumentos garantes de la igualdad y la dignidad humanas pero quizá no se contempla con la misma intensidad un derecho básico como es el de los padres a que sus hijos reciban la educación moral y religiosa de acuerdo con sus creencias. El estado confesional, tal y como lo configura la CP, no tiene por qué incidir negativamente en aquellos derechos más allá de unos ciertos privilegios en favor del catolicismo. Sin embargo habría que garantizar el derecho de cualquier ciudadano - sea cual fuere su religión- a que sus hijos reciban la educación que crea acorde con sus convicciones. Por ello quizá podría articularse un modelo de educación religiosa confesional en el que se contemplen las religiones más representativas del país $y$, su vez, una asignatura alternativa que garantizaría el derecho de quien decide que sus hijos no reciban educación religiosa. 
Enrique Herrera Ceballos: Aproximación a la Enseñanza de la Religión en el Sistema Jurídico Costarricense

Tal vez es hora de abordar definitivamente la reforma del modelo de Estado y apostar por la aconfesionalidad como principio informador del sistema de forma que la opción religiosa o arreligiosa del individuo resulte inocua. Y nos atrevemos a decir más. Tal vez sea también la hora de elaborar una Ley de Libertad Religiosa que concrete y desarrolle los derechos individuales y colectivos derivados del hecho religioso al modo en que existe no sólo en Europa sino en otros Estados latinoamericanos. 